\title{
SURGERY, GYNECOLOGY, OBSTETRICS AND GENITO-URINARY DISEASES
}

THE SYMPTOMS AND SURGICAL TREATMIENT OF CERTAIN CONDITIONS PRODUCED BY THE PRESENCE OF ADVENTITIOUS BANDS AND MEMIBRANES WITHIN. THE ABDOMINAL CAVITY, WITH REPORT OF TEN CASES.*

IYy R. Bland Williams, M.D., Surgeon, U. S. Navy.

The recognition of the presence of adventitious bands and membranes within the abdominal cavity is not new. Such structures were deseribed many years ago by Virchow; and more recently Jonnesco described a "parietocolic fold" and Treves a "bloodless fold." Similar structures have also been described by Reed, Juvara and others, but it was not until the writings of Lane and Jackson appeared that any great interest was taken in the matter. Besides these, many others have contributed to our knowledge of the subject, notably Binnie, Martin, Mayo, Coffey, Bainbridge, Pilcher, Frazier and Gerster. The membranes and bands and the effect produced thereby have been variously deseribed under such titles as "Chronic Constipation and Its Surgical Treatment" (Lane). "Pericolitis Dextra" (Binnie), "Mlembraneous Pericolitis" (Jackson), "Cecum Mobile" (Wilms), "Chronic Intestinal Stasis" (Lane), "Intestinal Obstruction Due to Kinks and Arlhesions of the Terminal Ileum" (Mayo), "Gastro-Intestinal Stasis" (Coffey), "Pericolic Membranes and Lane's Kink"' (Williams), etc.; and under these terms the various writers have described identical or very similar conditions.

Whether we accept the evolutionary theory of Lane, the congenital theory of Reed or Eastman, or the inflammatory theory of Pilcher, Gerster and others, there is no question that adventitious

\footnotetext{
-Read ly Title, Section on Surgerv, Southern Medical Ascoclation. Ninth Annual Meeting. Dal. las. Tex., Nov. 8-11, 1915.
}

bands and membranes are of very frequent occurrence, and in many instances produce serious consequences. Of the conditions brought about by the presence of these bands and membranes, by far the commoner and more important are:

1. The ileal or Lane's kink, produced by a band which extends from the right iliac fossa across the under surface of the ileal mesentery and is attached to the wall of the ileum within a few inches of the ileocecal valve.

2. Kinks and angulations of the terminal ileum produced by adherent appendices,-an appendix adherent to the under surface of the ileal mesentery causes a condition very similar to Lane's kink. Gross inflammatory adhesions may produce various angulations and kinkings of the terminal ileum and obstruction of a greater or lesser degree.

3. Angulation at the hepatic flexure and obstruction of the ascending colon by a pericolic or Jackson's membrane, which membrane extends from the parietal peritoneum to the outer side of the ascending colon, covers this structure and the hepatic flexure and loses itself in the wall of the gut near its internal longitudinal band. This structure contains fine blood vessels and connective tissue fibres. One or more of these bands may directly compress the gut, causing partial obstruction, or the membrane may angulate and kink the hepatic flexure, either by abnormally fixing this point, or by binding together the ascending and the beginning of the transverse colon.

4. A dilated and mobile cecum, by becoming prolapsed into the pelvis, will exaggerate any existing kink or obstruction at either the hepatic flexure or in the region of the ileocecal valve, and is in itself the cause of stagnation of the intestinal contents.

5. Angulation and obstruction at the hepatic flexure by a membrane which binds together the ascending colon and the first portion of the transverse colon. 
Such a membrane or adhesion is distinct from Jackson's membrane.

6. Marked prolapse of the transverse colon may in itself produce angulation and obstruction at the hepatic flexure and will exaggerate the obstruction produced by any co-existing membrane.

It may be noted that gastroptosis with pyloric oustruction or a generalized intestinal prolapse have not been mentioned, as these conditions are considered as distinct and separate from those produced by the presence of adventitious membranes and bands.

The symptoms produced by one or a combination of the conditions above outlined are those of chronic obstruction with intestinal auto-intoxication and may be enumerated as follows:

1. Apathy, loss of energy, easy fatigue, headache, backache, pain in the muscles and a general feeling of ill being.

2. Discoloration of the skin which becomes sallow ol muddy and occasionally spotted, dark rings appear beneath the eyes.

3. Coldness and claminess of hands and feet.

4. A foul breath, loss of appetite and very commonly a loss in weight.

5. Symptoms suggestive of neurasthenia.

6. Attacks of abdominal pain which are usually referred to the right side of the abdomen, not uncommonly to the region of the appendix. Such attacks may be preceded or followed by vomiting and may or may not be associated with taking of food.

7. Local tenderness which is confined to the region of the band or kink producing the obstruction. Thus tenderness in the right iliac region would suggest the presence of a Lane's kink or other obstructive factor in the region of the ileocecal valve, and tenderness over the hepatic flexure would indicate obstruction in that Iocality.

8. A sensation of distension by gas commonly confined to the right side of the abdomen. Not infrequently the distended cecum can be plainly outlined.

9. Constipation which is present in a great majority of the cases and is usually marked. Constipation often precedes the attacks of pain by many months and not infrequently it alternates with mucous diarrhea.

10. Bismuth radiographs are of the greatest value in clearing up the diagnosis. Normally the stomach should empty itself of the bismuth meal in about six hours, in about nine hours the bismuth should have passed the ileocecal valve, and in from twelve to eighteen hours the greater part of the bismuth should have passed the hepatic flexure. Marked departures from these figures tend to indicate obstruction. Frequently the kink or angulation can be plainly made out in the radiograph.

In any given case either the obstructive or toxic symptoms may predominate the one almost to the exclusion of the other, or symptoms of both obsfruction and intoxication may be present and well marked. In two of our cases symptoms of acute and absolute obstruction developed, requiring immediate operation. These cases are given in full under case reports.

The symptoms of a case of average severity are somewhat as follows: The patient gives a history of constipation extending over a period of months or years, of attacks of abdominal pain usually referred to the right side, not uncommonly to the region of the appendix, and perhaps of attacks of vomiting. He will tell you that he feels loggy and heary and that he tires easily and that he has no "ambition." Upon examination it will be found that he has a sallow complexion, that his hands are sweaty and cold and that his breath is offensive. Abdominal palpation will reveal a point of tenderness in the region of the appendix, usually somewhat lower down than the ordinary location of appendix tenderness or an area of maximum tenderness may be felt over the henatic flexure. Very frequently a distended cecum and ascending colon can be distinctly palpated. Given such symptoms a diagnosis of intestinal obstruction and stasis produced by either an ileal kink, an adherent appendix, a pericolic membrane or a mobile cecum is almost unavoidable. Not infrequently a case will nresent itself whose chief symptoms are frequent attacks of vomiting, occasionally occurring after every meal. In such a case the tenderness is apt to be most marked over the annendix region, and at operation a well-devel- 
oped Lane's kink produced by a broad, thick ileo-pelvic band will frequently be found to be the cause of the trouble. In sereril such cases the division of the band and plastic repair of the peritoneal defect completely and permanently cured the condition.

\section{TREATMENT.}

It is unquestionably true that much may be accomplished in certain cases of obstruction and stasis produced by one or more of the conditions above described by prolonged rest in bed, the administration of liquid petrolatum, forced feeding to increase the fat and thus give support to the prolapsed viscera (Jones' method) and by weturing supporting belts or mechanical spring supports to accomplish the same purpose. Such methods apply especially to women with relaxed abdominal walls. However, in cases such as those upon which this report is based, that is, more or less vigorous males between the ages of 20 and 45 years, such methods have little value. In these cases the abdominal wall is firm and muscular and any abdominal support can accomplish little or nothing. In such cases, operation offers the only hope of cure. We have employed the following operative procedures in all such cases with the greatest benefit.

In cases of obstruction produced by Lane's kink, the band causing the kink is divided transversely and the peritoneal defect thus produced is sutured at right angles to the line of division of the band. In some cases extensive undermining of the peritoneum is necessary to cover in the defect caused by a complete division of the band. It is extraordinary what a degree of angulation, kinking and obstruction can be completely relieved by this procedure.

In those cases of obstruction produced by an adherent appendix, the removal of the appendix will relieve the obstruction. In cases of obstruction by inflammatory adhesions, all such adhesions must be carefully separated, all peritoneal defects carefully covered and suture lines or any raw surfaces smeared with sterile vaseline.

A Jackson's membrane causing obstruction is divided to such an extent as is necessary to completely relieve the olstruc- tion, especial attention being given to the fibrous bands. Raw edges or any defects should be liberally smeared with sterile vaseline.

In cases of obstruction and stasis from a prolapsed and mobile cecum, this structure is to be fastened into its normal position by uniting its external longitudinal band to the parietal peritoneum along the line of meeting of the lateral and posterior abdominal walls by a number of interrupted linen sutures. In those cases in which the cecum is markedly dilated, its size is to be reduced by plication after the manner of Blake, - that is by uniting the anterior and external longitudinal bands by means of a continuous linen suture. The cecum is then fastened into its normal position in the manner above deseribed. It will be found that after fixing the cecum in this way it still has a slight range of mobility as if provided with a newly-formed mesentery.

Frequently the mobile and dilated cecum is associated with a pericolic membrane causing obstruction at the hepatic flexure and occasionally with an ileal kink as well, both of which conditions have also to be corrected.

In those cases in which a prolapsed transverse colon is believed to be the cause of the obstruction at the hepatic flexure, this structure may be lifted up and supported by uniting the great omentum transversely to the anterior abdominal wall above the umbilicus by a series of sutures as suggested by Coffey. It is well to add to this procedure a plication of the gastro-colic omentum. In three cases we have combined this method with the division of a pericolic membrane at the hepatic flexure with satisfactory results.

It may be noted that the operations of short circuiting and colectomy have not been mentioned in the above discussion. During the past three years we have operated upon 42 cases of chronic intestinal stasis due to one or more of the conditions above described, and in no case did either of these radical measures seem indicated. We have been able to trace a number of these cases for periods of one to two years or longer and in a very large nercentage of them the results have been excellent and the cure apparently permanent. In most cases the results are very striking. 
CASE REPORTS.

Case I.-W. I. I., age 22 years. Admitted January 21, 1915. Chief complaints: beadache, pain in right iliac region, constipation and malaise.

Two years and nine months ago appendectomy for acute appendicitis. Constipation for a year or more, steadily growing worse, feels dull and heavy all the time, attack of right iliac pain four months ago and a second about two days ago.

On admisston, of poor physique with sallow, muddy complexion.

On examination, there is rather marked tenderness over the appendix region and scar of former operation. Nine-hour bismuth radiograph shows marked ileal stasis with pudding.

February 16th. Operation.

Findings: Omentum adherent to caput coli and parietal peritoneum of the right iliac fossa, and a well marked ileal kink causing obstruction (the appendix had been removed). Adhesions separated and raw surfaces whipped over. The lleo-nelvic band divided transversely and the rent sutured longitudinally, thus entirely doing away with the obstruction.

The patient made an uneventful recovery from the operation. He was kept under observation until May 16, at which time he had gnined 15 pounds; his bowels moved daily, and his general appearance was greatly improved.

Case II.-H. M.. age 24 years. Admitted January 27,1915 . History of an attack of right iliac pain without nausen and vomiting about one and a half years ago, since which time he has been somewhat constipated. About two weeks ago felt pain in right iliac region, which has developed into a dull ache. Examination shows rather marked tenderness over the region of the appendix.

Bismuth radiograph shows marked nine-hour lleal stasis with puddline.

February 16, 1915. Operation.

McBurney's incision enlarged by opening the rectus sheath. The appendix, which is thickened and indurated and adherent to under surface of ileal mesenters, is removed. From the outer border of the appendix a peritoneal membrane extended to outer surface of cecum. Rather marked kinking of ileum about two inches from fleocecal ralve was corrected by the removal of the appendix.

Patient made an uneventful recovery from op. eration. He was last seen November 1 , and his general condition was decidedly improved. Constipation was less marked, although he still has to take an occasional purgative.

Case III.-S. L., age 23 years. Admitted June 2, 1915. Chief complaints: Indigestion, constipation, feeting "dopy" and having no ambition.

History of digestive disturbances for several years with pain or distress ahout one hour after menls. On almission is of poor physique with sallow, muddy skin.

Examination shows abdominal tenderness, de cldedly most marked over the region of the appendix, and marked relaxation of the lower abdomen. The patient is of a decidedly nerrous type.

Examination of the stomach contents normal. Radiograph shows nine-hour ileal stasis.
June 16, 1915. Operation.

A well marked Lane's kink corrected. An appendix, small and free and showing no signs of inflammation, removed.

Recovery from operation was unerentful. Before being allowed up a supporting belt was fitted and applied, which apparatus was constantly worn thereafter.

This patient was last seen about October 20 . He had gained in weight and his complexion had become almost ruddy. He was still somewhat constipated, for which liquid petrolatum was being regularly taken. His neurasthenic symptoms had largely disappeared.

Case IV.-R. B., age 28 years. Admitted April 7 , 1915. History of typhoid fever October and November, 1911; and since this time has had more or less continuous indigestion with pain and a feeling of fullness coming on two hours or more after eating, lasting several hours and relieved by food. Epigastrium is very tender. Has lost ten or fifteen pounds in weight.

On admission, a thin, wiry man of twenty-eight years. Examination negative save for a well marked tenderness in the right half of the epigas. trium. Radiographs show marked ptosis of cecum and transverse colon, the caput coli being lelow the brim of the true pelvis, and the transverse colon well down.

May 10, 1915. Operation. Ether. Through a right paracentral incision, a very long, free and thickened appendix is removed, and an excessively mobile and ptosed cecum is secured in approxl. mately its normal position by four sutures unit. ing its external longitudinal band to the posteriolateral wall of the abdomen. The gastro-colic omentum which is very long is shortened by four sutures, plicating the stomach, this membrane and the transverse colon. The great omentum at it colonic attachment is then sutured transversely to the anterior abdominal wall above the umbillcus.

May 19, 1915. Recovery uneventful. Bowels move more regularly than before operation. June 3. Improrement uninterrupted. Bowels move regularly. June 18. Discharged. Patient feels that he has been decidedly improved by operation. Constipation is much less marked and abdominal pain and discomfort have practically disappeared. Radiographs show that the cecum and transverse colon are in normal position.

Case V.-G. A. J., age 21 years. Admitted June 19. 1915. Apnendix removed 18 months ago, since which time there has been more or less constant abdominal pain and distress localized chiefly over the right side with marked constipation and occasional romiting. For past ten days bowels have not moved and romiting has nccurred whenever food was taken.

Examination shows a sallow man of 21 years with rather marked tenderness in the right side of the abdomen and some distention. June 22 . Has romited a number of times since admission and bowels only move by repeated enemas and then in extremely small amount.

June 23. Operation. Right rectus inctsion, ex cising scar of former operation. Abdomen entirelv iree from inflammatory adhesions.

Findings: A well marked Lane's kink. a Jackson's membrane binding down the hepatic flexure 
and rausing a practually complete obstruction at this point, and an extremely large and noblle

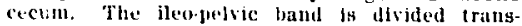
versoly and suturod longitudinilly; the Jaeks:on's membrame is dividled, freeing the lexure and reliteme the obstruction; and th. reilundant cectum is r. lured to normal size by unitint its ext*rmal and anterior lonfitudinal bands by a continuous stite: for a distance of is's inche's. And the ecerum thus roluecel is fastened to the posterio-literal abdombal wall by three pagenlatedue sutures.

Ju!y 5. Las mad. an absolute. unerentul re. covity bowels haw moved diby since second day ifter operation witiout purtitive or enema. Pati. nt feels greatly improved.

Alusut $i$. Has falmel in woight 7 pormuls; bowels move regularly. and the patlent is appar. entiy cured.

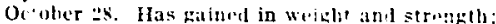
color food: botels move resularly without jur. fatix.. and the pationt is cured by the operation.

It illl be seen that life resulte in this case are very striking. At operatlon there vas practeally total ohstruction from a Jackion's membrant. The fatlent has male a complubt and absolute" reconery,

Ca: $t^{*}$ YI.-E. X. W.. age 2.2 bars. Aimithel Augu it 24,1915 . Trouble began elght months ds with pain ln right aldomen. Sisnll after this ho becante extremely constipated atul would hate la takt t mrative every fow days, afler which ha. woul: foel well for a day or $t$ wis. When another purgitive would be reiguled. Pith was very fre. quenty folt immediatoly after catlug. Durbins this gerion felt drowsy and sick all the timn

on admlsaton, a fitirly well-jourished, sillow man uf :-2 yars, complaining of rom-lipation and richt dbominal pain. Fxamination netitive say for a molderate tenilerness over llu ascenting colon and hepatic flexure.

lismuth raliograph shows markenl prolapse of the cerum. the caput colf being bolow the brim of the pelvis.

Aufist 31. taparotomy. Right piracentral in. cision. Cecum extremely movable. can be lifted out of the abdomen and across the midline. The ajpendix long and frou, showing no evidence of Inflanmatlon. removed, and the coevm ti fastenel in its normal position by thren lagenstecher stit.h. s ingerted through the extermal longitudinal band and along the line of junction of the posterlor and lateral abdominal walls.

September 28. The patlent made an unevent. ful rerovery and now has a dally bowel move. ment. His complexion has clearol ani? he eeels strune and vigorous.

Oetcher 10. Bowels are moving regularly witl. out jurkatives; complexion has clearol markedly, and ferels much stronger mind more active.

October 29. Discharted well: has rekidned nor. mal w.ight and strength, and has bean cured by th. of 'ration.

tase VII.C. G., aze 20 years. Mimited September 4. 1915. Past history univentfu!; lowels have always been regular. movine dully:

I'res.nt trouble: Nine days ago li. breame ronstif ated and his bowels did not move for four days. vhen, after repeated purgatives ant enemas. a tref evacintlon was obtained. For the past four diass there has been no movement or passing. of pas. For the past 48 hours there hits feren ratler severe ablominal pain and a ferlons of bruat depression.

On atmission, "xamfnation shows slight tenter. ness over the ascending colon "1t! markent $1 \mathrm{ym}$. piny and slight distunion in this region. Fom itina of bile (freonits fluid) occurs soon after admis sbul. Rejeatrol turpentine enemas fall to produce a movement or the pastitge of zass.

Operation about four hours after admisstom, under e.ther, right restus inctsion. The cectul and atcetiding colon are enormotisly dstated and irecls movable, and over the hepatic tlexure and de sctending colon is stretched a will martiel Jack son's membrane which causes constrietion and obstruction of the colon just frivximal (") the hepalle flexure. The terminal lloum is isumi dewn and angulated by an unusually woll level. ofwd latues band about four inches frum the

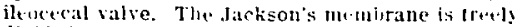
divided, entirely relfeving the obstruction: the

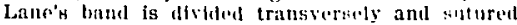
lotgitudimally; and ascending wion and i.rum rectuced in size by uniting the evernal and ante rior lonstudinal buthls by neans of a contumous suture t thakes methotl: and th. mobite crentm is fastened by four stitches to the angle of the lateral and postertur ablombal walls. Aavitite was don" before atul after the operation.

september 5 . I'roctoclysis and repeated tur

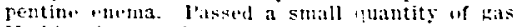
Nothing by mouth. Segtember i. Very coufort able. Suptember $i$ frepuenty repated emimas have bern fiven; bowels move wrll; lirge unmunt of fas expelled.

November 1. Hecostry complicalled with bu+ts monia berinting on thre twelfit lay. At protent is convalicicent. lowels have mowed regularly in stite of severe inti.rcurront illne

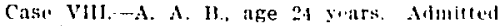
Sejtembir 14, 1915. History of ionstipat toll for three yias, requiring a purgative on the wa rase of $t$ wow a wek; of an attack of risht ilias min with romiting two sears ago and second similar nttack olle month itgo.

On sulnission. Well nourished nud of gooul phy. sique. (omplains of constipation. hoadacilt. ma laise and of feeline "Inped up" all the time.

Examination shows marbed tombrness : and to the inner sitle of Melburn+y"s point. Ills muth ratiograph sliows narked ninehour stastw in terminal roils of fleum.

Septemlier 16. Ojeration. Through a Mellur ney incision extendod by opening sheath of roc. tus, a lonts, free, non-inflamed anpendix removed. and an unusually woll marked Lane's hint cor rected by dividing the band transversoly and mit ing the rint logitulinally.

Octoher 15. Discharend. Bowels move rewl larly once a day and the patient stales that he. feels better than before operation. Complixiun has cleartil to a iery marked do:son. The im provement in this case is very striking.

Case IX.-C. L. B. nge 22 years. Aimitted NII. puse 18, 1915. Chine complaints: Indierstion censtipation, lack of enerky and disinclination for work. History of indigestion. with pain and dis tress after meals and constipation for the bast three years. During this neriod has had freytuent headaches nol has folt weak and liftless. Th. 
day before admission had an attack of right iliac pain with romiting.

September 27. Symptoms above noted have continued, and tenderness is definitely localized in the right iliac region. Bismuth radiograph shows nine-hour ileal stasis.

At operation, an appendix which is free and shows no evidence of intlammation is removed; and an unusually well marked Lane's kink is corrected by dividing the band transversely, loosening up the peritoneum and uniting the defect at right angles to the line of division of the band.

Novenber 1. Condition shows some improvement; constipation less marked.

Case X.-T. S., age 22 years. Admitted October 6. 1915. History of frequent attacks of right iliac pain and romiting for the past eight months and of constipation for past two months. For eight weeks or more has felt dull and listless and tired very easily.

Examination shows rather marked local tenderness in right iliac region below McBurney's point.

October 11. Abdominal section. A well marked Lane's kink causing obstruction is corrected in the maner described. An appendix showing no evidence of Inflammation is removed.

November 1. Uneventful recovery. Has had no pain or vomiting since operation. It is as yet too early to determine the result in this case.

\section{REFERENCES.}

(1) Lane, W. Arbuthnot: 1. "Chronic Constipation and Its Surgical Treatment." Brit. Medical Journal, 1905. 2. "Chronic Intestinal Stasis," Surg., Gyn. and Obst., Nov., 1910

(2) Binnie. J. It.: "Pericolitis Dextra," Monthy Cyclonedia of Practical Medicine, 1905.

(3) Iackson, Jabez N.: "Membranous Pericolitis," Surg,s Gyn. and Obst., Sept., 1909.

(4) Wilms: "Caecum Mobile," Zeit. fur Chir., 1908

(5) Mayo, Chas. H.: "Intestinal Obstruction due to Kinks and Adhesions of the Terminal Ileum," Surg, Gya.

(6) Coffey, R. C.: "The Principles Underlying the Surgical Treatment of Gastro-Intestinal Stasis," Surg., Gyn. and Obst., Oct., 1912 .

(7) Bainbridge, W. Seaman: 1. "The Surgical Treatment of Chronic Intestinal Stasis," Am. Jour. of GastroEnterology, July, 1913. 2. "A Contribution to the Sturly of Chronic Intestinal Stasis," Medical Record, Sept. 1913. 3. "The Significance of Intra-Abdominal Bands, Folds and Veils," Boston Ired. and Surg. Jour., Feb., 1914. 4. "Chronic Intestinat Stasis," The Wo: man's Ied. Jour., Jan., 1914.

(8) Williams, R. Bland:1. "Pericolic Membranes and Lane's Kink." Annals of Surgery, Jan., 1914. 2. "Chronic In. testinal Stasis as Produced by Obstruction in the IleoCecal Reginn and at the Hepatic Flexure," Annals of Surgery, Sept.. 1915.

\section{SIGNIFICANCE OF THE AMMONIA CO-EFFICIENT IN OBSTETRI-} CAL WORK.*

\section{BY JAMES R. GARBER, M.D., Birmingham, Ala.}

It has been succinctly remarked that the most beautiful thing of creation is the pregnant woman; and we find Shake-

* Read before the Jefferson County Medical Society, Birmingham, Ala., Feb. 14, 1916. speare alluding to "the pride of pregnancy." So, in the same ratio, is the parturient woman the most appealing, the most pitiful, the most helpless and the most tenderly cared for of all patients. And why is her condition modified by such adjectives? Because of the perilous and hazardous field she must enter for the sake of bearing an off-spring. In our college days the physiology and pathology of gestation and parturition are doled out in a serious and impressive manner, delineating the snares and pitfalls awaiting the woman if her attendant be ignorant, negligent or indifferent; and later, this elaboration is to be amplified by the master tutor EXPERIENCE. Nevertheless, despite careful and rigid attention to all the laws of the hygiene of pregnancy, certain complications are inevitable, chief of which is toxemia. Here I shall endeavor to discuss this phase of pregnancy in terms of ammonia and nitrogen, as found in a complete urinalysis.

The toxemia of pregnancy manifests itself in the form of pernicious nausea and vomiting and in eclampsia with or without convulsions; but, as the ammonia co-efficient work has to deal with the former our attention will be directed to the value of this co-efficient in cases of pernicious nausea and vomiting.

In adapting itself to the profound changes concomitant with pregnancy, the maternal organism might be declared in a state of war, endeavoring to maintain the neutrality of the blood vascular system, of the nervous system, of the excretory system, of the glands of internal secretion and of the many other vital systems of the human economy when vigorously attacked by the incongruous elements of reproduction. Hence, it is not asking too much of your imagination to assume that this constitutional shock is quite sufficient to cause such lesions of certain emunctory organs that would set up pathological conditions requiring the minute, immediate and careful study on the part of the physician. Of course, as outlined above, the nervous system or the excretory system or even the generative system might be the exciting influence in the condition we are to discuss. Therefore, an a priori conclusion might be deduced and for the sake of argument a definite classification of per- 